\title{
Erratum to: Dynamic activity analysis model-based win-win development forecasting under environment regulations in China
}

\author{
Shiyi Chen ${ }^{1}$ • Wolfgang K. Härdle ${ }^{2,3}$
}

Published online: 26 June 2015

C Springer-Verlag Berlin Heidelberg 2015

\section{Erratum to: Comput Stat (2014) 29:1543-1570 DOI 10.1007/s00180-014-0505-2}

The paper in 2014 Vol. 29 of Computational Statistics (COST) is a substantial extension of Chen (2010) Economic Research Journal (in Chinese). The authors would like to indicate that the reference to that paper was unfortunately missed in our COST paper.

\section{Reference}

Chen S (2010) Energy-save and emission-abate activity with its impact on industrial win-win development in China: 2009-2049. Econ Res J (in Chinese) 3:129-143

The online version of the original article can be found under doi:10.1007/s00180-014-0505-2.

Shiyi Chen

shiyichen@fudan.edu.cn

1 China Center for Economic Studies, School of Economics, Fudan University, Handan Road 220, Shanghai 200433, China

2 Center for Applied Statistics and Economics, Humboldt-Universität zu Berlin, Spandauer Straße 1, 10178 Berlin, Germany

3 Lee Kong Chian School of Business, Singapore Management University, Singapore, Singapore 